\title{
Relationship between the users' contact time in educational programs on diabetes mellitus and self-care skills and knowledge*
}

\author{
Associação do tempo de contato no programa educativo em diabetes \\ mellitus no conhecimento e habilidades de autocuidado \\ Asociación del tiempo de contacto en el programa educativo de diabetes \\ mellitus acerca del conocimiento y habilidades de autocuidado
}

\author{
Mariana Almeida Maia ${ }^{1}$, Ilka Afonso Reis ${ }^{2}$, Heloísa de Carvalho Torres ${ }^{1}$
}

How to cite this article:

Maia MA, Reis IA, Torres HC. Relationship between the users' contact time in educational programs on diabetes mellitus and self-care skills and knowledge. Rev Esc Enferm USP. 2016;50(1):59-64. DOI: http://dx.doi.org/10.1590/S0080-623420160000100008

\begin{abstract}
* Extracted from the dissertation "Associação entre o tempo de contato na prática educativa e seu impacto no conhecimento, atitude e autocuidado em diabetes mellitus", Universidade Federal de Minas Gerais, 2015.

${ }^{1}$ Universidade Federal de Minas Gerais, Escola de Enfermagem, Belo Horizonte, MG, Brazil.

${ }^{2}$ Universidade Federal de Minas Gerais, Departamento de Estatística, Belo Horizonte, MG, Brazil.
\end{abstract}

\begin{abstract}
Objective: Check the relationship between the users' contact time in educational programs and self-care and knowledge variables in diabetes mellitus. Method: A longitudinal study with a quantitative approach with the participation, in the initial phase, of 263 users linked to Basic Health Units in Belo Horizonte, Brazil during the years 2012 and 2013. The data were collected with respect to the total contact time of the users' participation in the educational program as regards knowledge and self-care in acquired diabetes mellitus. The data were analyzed using the Student t-test for comparison of means, considering a 0.05 significance level. Results: The final sample included 151 users. The analysis showed that the improvement in self-care scores was statistically higher during an educational intervention of eight hours or more ( $\mathrm{p}$-value $<0.05$ ). In relation to the scores for knowledge, there was a statistically significant improvement at the end of the educational program. It was not possible to identify a value for the contact time from which there was an increase in mean scores for the ability of knowledge. Conclusion: To improve the effectiveness of the promotion of skills related to knowledge and self-care in diabetes mellitus, it is necessary to consider the contact time as a relevant factor of the educational program.
\end{abstract}

\section{DESCRIPTORS}

Health Education; Diabetes Mellitus; Knowledge; Self Care; Public Health Nursing.

\author{
Corresponding author: \\ Mariana Almeida Maia \\ Universidade Federal de Minas Gerais \\ Escola de Enfermagem \\ Av. Prof. Alfredo Balena, 190 \\ Sala 520 - Santa Efigênia \\ CEP 30130-100 - Belo Horizonte, MG, Brazil \\ marianasmart2@yahoo.com.br
}

Received: 07/14/2014

Approved: 11/17/2015 


\section{INTRODUCTION}

Diabetes mellitus stands out for having low rates of adherence to treatment, mainly because it requires self-care in the long term. However, the carrying out of educational interventions shows that many complications can be prevented through strict control of glucose levels in the blood ${ }^{(1-4)}$.

Thus, it is argued that education for care in diabetes mellitus is relevant, because the user with this condition needs to develop self-care skills, such as following a healthy diet, engaging in physical activities, monitoring blood glucose, and taking medication have a good capacity for problem solving and adopt healthy behaviors to prevent complications ${ }^{(2,5)}$. In addition, the literature indicates the time of participation in educational programs as an important factor, and it presents studies that prove the effectiveness of interventions of both long and short duration ${ }^{(4,6)}$.

Regarding the forms of measurement of the effect of an intervention, a meta-analysis conducted on eight scientific databases, and which included original studies of randomized clinical trials, revealed that the duration of the intervention influenced its effect. However, as this is a factor that is difficult to analyze, due to difficulties linked to the descriptions of the interventions, it was not possible to deduce whether the intensity of the session was defined by the number of contacts or the number of hours with the user with diabetes ${ }^{(7)}$.

In this context, aiming to promote educational actions for self-care in diabetes, and the consequent improvement in metabolic control and user quality of life, the Universidade Federal de Minas Gerais, in partnership with the Basic Health Units, developed an educational program in diabetes mellitus, involving educational interventions and user contact time in the educational program.

Regarding the contact time (duration of educational practice), it is important to clarify that it varies depending on the program objective. In other words, the amount of contact time spent with users with diabetes in order to develop their autonomy is distinct from that which aims to make them responsible for their health ${ }^{(7-9)}$.

Based on what has been presented, it is argued that the present study is justified based on the fact that there is little research in the national and international literature that assesses the impact of contact time on the results of educational programs for diabetes mellitus ${ }^{(4)}$. This gap was also identified by a meta-analysis study, which stressed that more studies on the frequency and duration of intervention could provide useful information for the effectiveness of educational interventions ${ }^{(8-9)}$. The study also highlights the benefits generated by educational interventions in the treatment of diabetes mellitus.

Therefore, it is expected that this work will guide interventions for the promotion and prevention of diabetes mellitus, through an educational program with emphasis on the contact time during the educational practice.

In this sense, this study aims to determine the relationship between the contact time of the users in educational programs and the variables of knowledge and self-care in diabetes mellitus.

\section{METHOD}

The study reported in this article was of the longitudinal, descriptive and quantitative type. The study population consisted of patients with type 2 diabetes mellitus, of both sexes, aged between 30 and 85 years, attended in four Basic Health Units (BHU) in the Eastern Region of Belo Horizonte (state of Minas Gerais), during 24 months in the years 2012 and 2013.

Study data derived from an experimental study, generated from a sample formed by the data collected in the intervention group. The study had the participation of 236 users with early-onset diabetes mellitus. The inclusion criteria were: Users could not 1) have participated in a previous education program, which was recorded in the first interview; or 2) have chronic complications (neuropathy, nephropathy, diabetic retinopathy, and/or peripheral arterial disease), which was recorded in the user's medical records.

Users who met the inclusion criteria were selected and invited to participate. The educational program was developed in four cycles lasting for one month followed by an interval of three months, and featured three educational strategies: group education; home visit; and telephone intervention. The first strategy used was group education. If the user could not attend the meeting, home visits or telephone interventions were carried out, which allowed greater participation of users in the diabetes education program.

However, throughout the educational intervention, there was a loss of $30 \%$ of the participants, leaving 151 users in the final phase. Among the main reasons were: a lack of interest in participating in the study; change of address; complications of diabetes mellitus (diabetic retinopathy, diabetic foot, and others); and death. Thus, the analysis presented in this article was conducted with the sample of 151 users with type 2 diabetes mellitus.

The methodology was planned to discuss the themes and subjects proposed in each cycle. Educational interventions count on the participation of professionals in the health area (nurses, nutritionists, physiotherapists, physical educators, and doctors) for group education. Home visits and telephone interventions were performed by nurses and nutritionists.

The content covered in the three educational interventions, such as the eating plan, physical activity, feelings, barriers, and goals for self-care practices, were discussed through dialogic practice to stimulate the user's reflection on their care for their health. This theme was discussed in all cycles following the target plan that was established with the user.

Each strategy was planned with a view to a specific contact time during the educational program, so that the relevant issues were addressed in each cycle. Each user had at least four and a maximum of 12 contacts with the professional from the Health area, totaling 14 hours of participation in the educational program. In addition, all 151 users had at least one contact with the professional in each cycle, especially for those who were part of the cycle for home visits or telephone interventions. 
Thus, group education had a 90-minute contact time at each meeting, where the average participation was with 10 members, with three meetings per cycle. The meetings took place in the boardroom of the health units. Home visits had an average duration of 60 minutes, accounting for one contact per cycle, while the telephone intervention was done through one contact via phone call per cycle, with an average duration of 25 minutes. Altogether, there were four contact calls. Thus, at the end of the educational program, the strategies had a total contact time of 14 hours for the operative group, four hours for home visits, and one hour and 40 minutes for the telephone interventions.

To collect data, users answered a sociodemographic questionnaire at the beginning of the educational practice (T0) that addressed age, sex, education, marital status, occupation, duration of treatment, and monthly income. Two instruments were also applied, already translated and validated, both at baseline (T0) and at the end time (TF) of the education program: General Knowledge of the Disease $(\mathrm{DKN}-\mathrm{A})^{(10)}$ and Self-Care in Diabetes $(\mathrm{ESM})^{(11)}$.

The DKN-A knowledge test is a self-completion questionnaire with 15 multiple-choice items on different aspects related to general knowledge about diabetes mellitus. The measuring scale ranges from 0 to 15 points and each item is measured with a score for the correct answer and zero for an incorrect one. In order to be considered an improvement in awareness of diabetes mellitus, the user needed to score at least eight points ${ }^{(10)}$.

The ESM test is a self-care in diabetes mellitus questionnaire that measures adherence to self-care activities in the diabetic user within seven days prior to the questionnaire, referring to physical activity and healthy eating. It has eight closed and self-completing questions, having a total score of eight points. To show a change in behavior on the part of the user, the minimum score is five points ${ }^{(11)}$.

To analyze the relationship between the contact time and the variables of knowledge and self-care in diabetes mellitus, the contact time was divided into two categories, based on the use of cut-off points in an interval of two to 13 hours. The final cut-off point was defined as one in which the two categories of time had on average statistically different results.

Data analyses were performed using the statistical programming environment $\mathrm{R}$ (version 3.0.1). The following statistical tests were performed: 1 ) Student t-test paired to compare the mean scores in the T0 and TF times; 2) Student $\mathrm{t}$-test for independent samples, in order to compare the mean differences of scores in the two time intervals defined by the cut-off point; and 3) Shapiro-Wilk test to verify the assumption of the normality of the data. For all of the analyses, significance was set at $\mathrm{p}<0,05$.

The study was approved by the Ethics Committee at the Universidade Federal de Minas Gerais, under Opinion No. 509.592, from 01/10/2014, having fulfilled all of the requirements established by Resolution no. 466/12, of the National Health Council.

\section{RESULTS}

The sample of 151 users with diabetes who remained until the end of the study was characterized as regards the demographic data collected at the end time (T0). The age ranged between 39 and 83 years, with a mean of 64.1 years $(\mathrm{SD}=9.80)$. Most were female $(76.8 \%)$, lived with a partner (52.3\%), and had a time of evolution of diabetes mellitus of less than 10 years (56.3\%). Regarding occupation, $77.5 \%$ of users said they were not working. It was also observed that $16.5 \%$ of users said they were illiterate.

In the group of users that were lost, the average age was 58.8 years $(\mathrm{SD}=10.21), 61.8 \%$ were female, $16.8 \%$ were illiterate, $71.9 \%$ said they were not working, and $52.8 \%$ lived with a partner. Comparison of the two groups, in terms of sociodemographic characteristics, showed no statistical evidence of non-random loss, except as regards sex, because the group that remained in the study had a higher proportion of women than the user group that left the study (Pearson's chi-square test; $\mathrm{p}$-value $=0.022$ ).

With respect to the variables of knowledge (DKN-A) and self-care (ESM) at the moments of T0 and TF, the results are presented in Table 1.

Table 1 - Comparison of the scores for the questionnaires (DKNA, ESM) between the initial time (T0) and the end time (TF) - Belo Horizonte, Minas Gerais, Brazil, 2014.

\begin{tabular}{lccccc}
\hline $\begin{array}{l}\text { Questionnaires } \\
\text { Scores }\end{array}$ & $\begin{array}{c}\text { T0 } \\
\text { Mean } \\
\text { (SD) }\end{array}$ & $\begin{array}{c}\text { TF } \\
\text { Mean } \\
\text { (SD) }\end{array}$ & $\begin{array}{c}\text { Mean } \\
\text { difference, } \\
\text { TF-T0 } \\
\text { (SD) }\end{array}$ & p-value* & CI 95\% \\
\hline DKNA & 7.36 & 8.83 & 1.47 & $<0.001$ & 1.01 to \\
Knowledge & $(2.77)$ & $(2.50)$ & $(2.87)$ & & 1.93 \\
ESM & 3.46 & 3.88 & 0.42 & $<0.001$ & 0.19 to \\
Self-care & $(0.44)$ & $(1.38)$ & $(1.44)$ & & 0.65 \\
\hline
\end{tabular}

Source: Prepared by the authors. Note: $n=151$

*Test conducted: Student t-test.

From the analysis of the data for the differences between the scores presented, it can be said that the mean scores for the measuring instruments (DKN-A and ESM) at the $\mathrm{T} 0$ and $\mathrm{TF}$ times can be considered statistically different at a significance level of 5\%. Data analysis also showed that there was an average increase in scores between $\mathrm{T} 0$ and $\mathrm{TF}$, for both the knowledge variable and the self-care variable.

Table 2 presents the analysis of the relationship between the contact time and the self-care variable (ESM). In the interval of eight to 14 hours, a statistically significant increase was detected in the ESM mean score between the T0 and $\mathrm{TF}$ times (CI of 95\%, 0.31 to 1.04). However, in the time interval of up to eight hours, a statistically significant change in the ESM mean score was detected. The interval of eight to 14 hours, in turn, had a statistically different mean effect (TF-T0) in relation to the mean effect obtained in the interval from one to seven hours $(0.67 \pm 1.55$ against $0.19 \pm 1.30$ respectively).

Unlike the self-care variable, it was not possible to identify a cut-off point for the contact time from which the mean effect (TF-T0) in the knowledge scores (DKN-A) was different from the mean effect before this cut-off point. 
Table 2 - Ratio between the contact time and the self-care variable in the ESM questionnaire - Belo Horizonte, Minas Gerais, Brazil, 2014.

\begin{tabular}{lcccccc}
\hline Time (hours) & $\mathbf{N}$ (Total users) & ESM score Mean difference (SD) & p-value* & Cl 95\% * & p-value** & Cl 95\%** \\
\hline $\mathbf{1} \mid \mathbf{- 8}$ & 79 & $0.19(1.30)$ & 0.204 & -0.10 to 0.48 & 0.0399 & 0.02 to 0.95 \\
$\mathbf{8} \mid-\mathbf{1 4}$ & 72 & $0.67^{*}(1.55)$ & $<0.001$ & 0.31 to 1.04 & \\
\hline
\end{tabular}

Source: Prepared by the authors. Note: $n=151$

\#Effects (TF-T0) means are statistically different between the time intervals ( $\mathrm{p}$-value $=0.0399)$. ${ }^{*}$ Test conducted: Student t-test. Confidence intervals and significance test for the mean of the difference between the beginning and end of the study (T0-TF). ${ }^{* *}$ Confidence interval and significance test for the difference between the means of the effect (TF-T0) in the first and second time interval.

\section{DISCUSSION}

This study differs from others, as it examines the relationship between the contact time and the variables of knowledge and self-care to control diabetes mellitus. In this sense, it is observed that the participation of users in short and long-term educational practice shows favorable results for the control of diabetes mellitus. Other studies also indicate, as a basic principle, that the greatest effect of education is observed immediately after the end of the intervention with the reduction of glycohemoglobin. Moreover, it is argued that repetition of the information is necessary because it allows users to reflect on their attitudes toward confrontation and their knowledge about their chronic condition. This is a relevant question, given that behavioral changes do not occur quickly and vary from user to user ${ }^{(4,12)}$.

In relation to the user's knowledge of diabetes mellitus, there was an improvement in the average of the scores for knowledge, noting that this variable corresponds to a set of information that users need to have in order to be able to take care of their health ${ }^{(12-13)}$. However, unlike the self-care ability, it was not possible to identify a value for contact time between one and 14 hours, from which there was a greater increase in average scores for the knowledge ability.

It is important to know the cutoff points for the contact time from which an improvement in the skills of the users takes place, as this will enable health educators to determine emphases during the education process, especially in the case of users with permanent low knowledge or low selfcare regarding their chronic condition.

On the other hand, one could argue that the educational intervention using the face-to-face and individual approach strategies may have contributed to the improvement of selfcare with diabetes mellitus due to a detriment of knowledge, by engaging the practice of the users more in their day-today lives.

As a complement, a study that involves the participation of users for in a five-year educational program is cited, in which the researchers recommended that education encompass an ongoing effort to acquire knowledge with the aim of getting users to adopt lasting self-care behavior. Therefore, it is believed that the educational process should be permanent in order to ensure strengthening of the knowledge acquired ${ }^{(13-14)}$.

In this sense, this study enabled us to verify that, for self-care ability, the longer the time of contact with the user during the educational program the better the outcome of care in the treatment of diabetes mellitus. The time interval between eight and 14 hours showed, on average, better user response to the educational program with respect to the self-care of diabetes.
Regarding the relationship between the contact time and reducing glycohemoglobin, there are studies that show a lack of relationship between these variables ${ }^{(4,9)}$. These studies, however, have determined what features of interventions have the greatest effect on glycemic control, and among them is the contact time.

Currently, at the same time, several studies have shown favorable results with regard to glycemic control and the ability to control diabetes mellitus. Educational programs, either carried out in the short or long term, have been described in the literature as an important strategy to promote this control, although most references only contemplate the results obtained. Thus, it is argued that the implementation process needs to be better described, as well as its impact on the variables of evaluated control ${ }^{(8,15)}$.

Education, in turn, allows one to transmit information to help users in the acquisition of skills for the control of diabetes and their self-care, and it allows the appreciation of the need to sensitize the user to the risk factors. However, it is possible that self-care behaviors vary over time in response to changes in personal and environmental factors ${ }^{(3,16)}$.

This is because the self-care ability of the user is linked to multiple factors, such as planning goals and confronting barriers. Among the barriers, the challenges are in adherence to healthy eating, in the practice of physical activity, in glucose monitoring, and in drug therapy ${ }^{(17)}$. Therefore, this aspect allows for strengthening the participation of health professionals in the development of educational programs, which is an important factor, because studies point to the existence of a direct influence of the total contact time between the user and the educator in terms of optimal program results ${ }^{(4,16,18)}$.

In addition, studies have pointed out, among their key findings, the benefits obtained by educational interventions in the treatment and control of diabetes mellitus. The importance of considering the knowledge, attitudes, and care practices with diabetes as constituting skills also stands out, so that one can understand the behavior observed and guide its change $\mathrm{e}^{(8-9)}$. Thus, the contact time variable becomes feasible for measuring the association with the skills needed to control diabetes mellitus, thus verifying the influence on users' self-care practices.

For this study, the duration of contact time between health professionals and users was 14 hours. The results reveal that the amount of time spent in the educational program is associated with the users' acquisition of knowledge and the improvement of their self-care. This result, coming from a long-term educational program, can be an indicator 
for the importance of developing educational interventions with this segment, as also observed in other studies ${ }^{(7)}$.

Moreover, the contact time with the health professional seems to be the main predictor for the reduction of glycohemoglobin. It is estimated that to obtain a reduction of $1 \%, 23.6$ hours of contact with the professional would be necessary. In another study, which presents the result of increased knowledge in relation to the contact time in the educational program, each user had eight hours of contact with the professional and the glycohemoglobin level of these users fell $0.41 \%$ on average. The authors ensured that all conditions were the same for both groups (control and intervention); however, the control group failed to improve their knowledge score. It was also observed by the authors that it is not only the professional-user contact, but also the time of educational exposure, that determines changes in attitudes ${ }^{(4,8)}$.

One can also mention the example of a meta-analysis that evaluated the effect of educational interventions (clinical trials) in the treatment of diabetes mellitus. The interventions were grouped according to their duration and into three categories: 13 weeks or less, $14-26$ weeks, and 27 weeks or more. The results suggest that interventions over a 14-26 week period proved more significant than those with an interval of 27 weeks or more in reducing glycohemoglobin. They also indicate that interventions performed by nurses were more successful than those made by other categories of health professionals ${ }^{(6)}$.

Even so, it is suggested that there is a need for more research on the frequency and duration of the intervention, which could provide useful information for identification of a more effective strategy, in addition to allowing a comparison of the contact time applied in educational practices and the variables of knowledge and self-care in diabetes mellitus.

Another factor to be explored is a meta-analysis of randomized studies ${ }^{(8)}$. The study revealed that the contact time during the intervention influenced its effectiveness on improving knowledge and the practice of self-care. In other words, analysis of the study showed that there is a positive correlation between the users' knowledge and the number of contacts made during an educational intervention directed towards the care of diabetes mellitus in the past two years ${ }^{(8)}$.
Thus, it is argued that it is important to distinguish whether this aspect of an educational program directly influences the expected results. This study shows that a systematic educational program, associated with the contact time between users and health professionals, has an influence on the improvement of self-care, providing a healthy lifestyle for the user. Even if the result was not statistically significant, it was observed that, in this sample of users, the contact time and the number of sessions in the strategies used during the educational program provided an improvement in knowledge, contributing to a change in user behavior with the goal of the metabolic control of diabetes mellitus ${ }^{(8,10,17)}$.

In addition, although the literature highlights the difficulty in making changes and maintaining the user's lifestyle ${ }^{(19)}$, the results of this study indicate the need to direct the educational program to the thematic change in behavior, acting so as to lead the user to reflect on their selfcare behaviors. In this respect, the user contact time in the educational program was considered effective, reflected in the improvement of their knowledge. Thus, it has to be the user's reflection on the state of their health and possible forms of care that involves changing their attitude toward diabetes mellitus.

This study has the limitation of not comparing the results with that of a control group to see whether differences would be verified in the skills for the knowledge and self-care of the user who does not participate in a structured educational program. Furthermore, the predominance of female users in the sample may have contributed to the results, as women value self-care more ${ }^{(20)}$. Therefore, it is suggested to conduct studies that enable further research and results as regards knowledge and the relationship between contact time and the ability for self-care in diabetes mellitus.

\section{CONCLUSION}

The participants in this study started the educational program having poor knowledge and little care for the control of diabetes mellitus. However, with their participation in the program it was possible to raise their level of knowledge and improve their self-care. Accordingly, it was found that the longer the user's contact time with the educational program, the greater the improvement registered in the practice of self-care.

\section{RESUMO}

Objetivo: Verificar a relação entre o tempo de contato de usuários em programas educativos e as variáveis conhecimento e autocuidado em diabetes mellitus. Método: Estudo longitudinal de abordagem quantitativa, com a participação, na fase inicial, de 263 usuários vinculados às Unidades Básicas de Saúde de Belo Horizonte, Brasil, durante os anos de 2012 e 2013. Foram coletados dados com relação ao tempo de contato total de participação dos usuários no programa educativo, quanto aos conhecimentos e ao autocuidado em diabetes mellitus adquiridos. Os dados foram analisados por meio do teste t-Student para a comparação de médias, considerando um nível de significância de 0,05. Resultados: A amostra final resultou em 151 usuários. A análise revelou que a melhora nos escores de autocuidado foi estatisticamente maior durante a intervenção educativa de 8 horas ou mais (valor-p $<0,05$ ). No respeito aos escores de conhecimentos, houve melhora estatisticamente significativa ao final do programa educativo. Não foi possível identificar um valor para o tempo de contato a partir do qual houvesse um aumento dos escores médios para a habilidade do conhecimento. Conclusão: Para melhorar a efetividade da promoção das habilidades relacionadas ao conhecimento e ao autocuidado em diabetes mellitus, é necessário considerar o tempo de contato como fator relevante do programa educativo.

\section{DESCRITORES}

Educação em Saúde; Diabetes Mellitus; Conhecimento; Autocuidado; Enfermagem em Saúde Pública. 
RESUMEN

Objetivo: Verificar la relación entre el tiempo de contacto de usuarios en programas educativos y las variables conocimiento y autocuidado en Diabetes mellitus. Método: Estudio longitudinal de abordaje cuantitativo, con la participación, en la fase inicial, de 263 usuarios vinculados a las Unidades Básicas de Salud de Belo Horizonte, Brasil, durante los años de 2012 y 2013. Fueron recogidos datos con relación al tiempo de contacto total de participación de los usuarios en el programa educativo, en cuanto a los conocimientos y el autocuidado en Diabetes mellitus adquiridos. Los datos fueron analizados mediante el test t de Student para comparación de promedios, considerando un nivel de significación del 0,05. Resultados: La muestra final tuvo como resultado 151 usuarios. El análisis reveló que la mejora en los puntajes de autocuidado fue estadísticamente mayor durante la intervención educativa de 8 horas o más (valor-p < 0,05). En lo que se refiere a los puntajes de conocimientos, hubo mejora estadísticamente significativa al final del programa educativo. No fue posible identificar un valor para el tiempo de contacto desde el que hubiera un incremento de los puntajes medios para la habilidad del conocimiento. Conclusión: Para mejorar la efectividad de la promoción de las habilidades relacionadas con el conocimiento y el autocuidado en Diabetes mellitus, es necesario considerar el tiempo de contacto como factor relevante del programa educativo.

\section{DESCRIPTORES}

Educación en Salud; Diabetes Mellitus; Conocimiento; Autocuidado; Enfermería en Salud Pública.

\section{REFERENCES}

1. Torres HC, Santos LM, Cordeiro PMCS. Home visit: an educational health strategy for self-care in diabetes. Acta Paul Enferm [Internet]. 2014 [cited 2015 July 10]; 27(1):23-8. Available from: http://www.scielo.br/pdf/ape/v27n1/0103-2100-ape-27-01-00023.pdf

2. Ramadas A, Chan CK, Oldenburg B, Hussien Z, Quek KF. A web-based dietary intervention for people with type 2 diabetes: development, implementation, and evaluation. Int J Behav Med. 2015;22(3):365-73.

3. Ferguson S, Swan M, Smaldone A. Does diabetes self-management education in conjunction with primary care improve glycemic control in Hispanic patients? A systematic review and meta-analysis. Diabetes Educ. 2015;41(4):472-84.

4. Sherifali D, Bai JW, Kenny M, Warren R, Ali MU. Diabetes self-management programmes in older adults: a systematic review and metaanalysis. Diabet Med. 2015;32(11):1404-14.

5. Martinez Y, Campbell SM, Hann M, Bower P. The relationship between quality of care and self-management in patients with type 2 diabetes: a cross-sectional survey in primary care in Mexico. Qual Prim Care. 2014;22(6):262-9.

6. Klein HA, Jackson SM, Street K, Whitacre JC, Klein G. Diabetes self-management education: miles to go. Nurs Res Pract. 2013;2013:581012.

7. Endevelt R, Peled R, Azrad A, Kowen G, Valinsky L, Heymann AD. Diabetes prevention program in a Mediterranean environment: individual or group therapy? An effectiveness evaluation. Prim Care Diabetes. 2015;9(2):89-95.

8. Al-Maskari F, El-Sadig M, Al-Kaabi JM, Afandi B, Nagelkerke N, Yeatts KB. Knowledge, attitude and practices of diabetic patients in the United Arab Emirates. PLoS One. 2013;8(1):e52857.

9. Borhani M, Rastgarimehr B, Shafieyan Z, Mansourian M, Hoseini SM, Arzaghi SM, et al. Effects of predisposing, reinforcing and enabling factors on self-care behaviors of the patients with diabetes mellitus in the Minoodasht city, Iran. J Diabetes Metab Disord. 2015;14:27.

10. Torres HC, Virginia AH, Schall VT. Validação dos questionários de conhecimento (DKN-A) e atitude (ATT-19) de Diabetes Mellitus. Rev Saúde Pública [Internet]. 2005 [citado 2015 out. 16];39(6):906-11. Disponível em: http://www.scielo.br/pdf/rsp/v39n6/26984.pdf

11. Torres HC, Franco LJ, Stradioto MA, Hortale VA, Schall VT. Evaluation of a diabetes education program. Rev Saúde Pública [Internet]. 2009 [cited 2014 Dec 01];43(2):291-8. Available from: http://www.scielo.br/pdf/rsp/v43n2/en_05.pdf

12. Bhutani G, Kalra S, Lamba S, Verma PK, Saini R, Grewal M. Effect of diabetic education on the knowledge, attitude and practices of diabetic patients towards prevention of hypoglycemia. Indian J Endocrinol Metab. 2015;19(3):383-6.

13. Chagas IA, Camilo J, Santos MA, Rodrigues FFL, Arrelias CCA, Teixeira CRS, et al. Patients' knowledge of Diabetes five years after the end of an educational program. Rev Esc Enferm USP [Internet]. 2013 [cited 2015 July 10];47(5): 1137-42. Available from: http://www.scielo. $\mathrm{br} / \mathrm{pdf} / \mathrm{reeusp} / \mathrm{v} 47 \mathrm{n} 5 / 0080-6234-$-reeusp-47-05-1137.pdf

14. Dube L, Van den Broucke S, Housiaux M, Dhoore W, Rendall-Mkosi K. Type 2 diabetes self-management education programs in high and low mortality developing countries: a systematic review. Diabetes Educ. 2015;41(1):69-85.

15. Marques MB, Silva MJ, Coutinho JFV, Lopes MVO. Assessment of self-care competence of elderly people with diabetes. Rev Esc Enferm USP [Internet]. 2013 [cited 2015 July 10]; 47(2): 415-20. Available from: http://www.scielo.br/pdf/reeusp/v47n2/en_20.pdf

16. Small N, Bower P, Chew-Graham CA, Whalley D, Protheroe J. Patient empowerment in long-term conditions: development and preliminary testing of a new measure. BMC Health Serv Res. 2013;13:263.

17. Erickson D. Barriers to physical activity in people with type 2 diabetes enrolled in a worksite diabetes disease management program. Diabetes Educ. 2013;39(5):626-34.

18. Lepard MG, Joseph AL, Agne AA, Cherrington AL. Diabetes self-management interventions for adults with type 2 diabetes living in rural areas: a systematic literature review. Curr Diab Rep. 2015;15(6):608.

19. Dyke ML, Cuffee YL, Halanych JH, McManus RH, Curtin C, Allison JJ. The relationship between coping styles in response to unfair treatment and understanding of diabetes self-care. Diabetes Educ. 2013;39(6):848-55.

20. Littlewood K, Cummings DM, Lutes L, Solar C. Psychometric Properties of the Family Support Scale adapted for African American Women with Type 2 Diabetes Mellitus. Ethn Dis. 2015;25(2):193-9.

Financial Support: BRIDGES - International Diabetes Federation Program - Lilly Diabetes Educational Scholarship. 